\title{
Development of Oxidative Pyrolysis Method for the Rapid Determination of Boron in Graphite Powders by Inductively Coupled Plasma Optical Emission Spectrometry (ICP-OES)
}

\author{
M.V. Balarama Krishna •, K. Chandrasekaran, S. Thangavel, and D. Karunasagar \\ National Center for Compositional Characterization of Materials (NCCCM) \\ Bhabha Atomic Research Centre \\ Department of Atomic Energy, Hyderabad - 500 062, India
}

\section{INTRODUCTION}

Because of outstanding properties such as low neutron absorption cross-section, good moderating properties, chemical inertness, capacity to withstand very high temperatures, high thermal and electrical conductivity, graphite is largely used as a moderator, reflector, and structural material in nuclear reactors $(1,2)$. Graphite is also the base material for the preparation of mixed carbide fuels (e.g., $(\mathrm{U}, \mathrm{Pu}) \mathrm{C})$ for the fast breeder reactors (FBR) and also has widespread industrial applications (e.g., as electrodes, crucibles, high-resistance engineering parts in the aerospace technology) (3-9). For such applications, high purity graphite is essential because the outstanding properties, in particular, the nuclear properties of graphite are strongly influenced by the presence of impurities even at low concentrations. The concentration of boron in nuclear-grade graphite is of particular concern among the other impurities due to its high neutron absorption cross-section for thermal neutrons (3837 b and $5 \mathrm{mb}$ for ${ }^{10} \mathrm{~B}$ and ${ }^{11} \mathrm{~B}$, respectively). Hence, highpurity graphite for nuclear purposes (i.e., nuclear-grade graphite) necessitates a strict control of boron whose specification limit has been set as $5 \mu \mathrm{g} \mathrm{g}^{-1}$ (10). The Department of Customs and Central Excise, Government of India, mandates that any graphite consignment that is

\footnotetext{
*Corresponding author.

:E-mail: balaram@cccm.gov.in

Tel: +914027121365

Fax: +914027125463
}

\section{ABSTRACT}
Oxidative pyrolysis (OP) was applied for the determination of boron in graphite powders by inductively coupled plasma opti- cal emission spectrometry (ICP- OES). A known amount of graphite powder ( $\sim 0.2 \mathrm{~g})$ was mixed with carbon powder (1:0.75) along with $5 \mathrm{mg}$ of $\mathrm{Na}_{2} \mathrm{CO}_{3}(250 \mu \mathrm{L}$ of $20 \mathrm{mg} \mathrm{mL}^{-1}$ solution) and an appropriate amount of polyvinyl alcohol (binder). After drying under the IR lamp, the sample mixture was pressed into a pellet which was placed into a boat and introduced into the in-house pyrolysis chamber. The chamber was then heated using a Bunsen burner in the presence of an oxygen stream. The pyrolysis process commenced when the temperature reached $\sim 400{ }^{\circ} \mathrm{C}$ and was completed in 5 minutes when $\sim 0.2 \mathrm{~g}$ of graphite powder was used. After allowing the chamber to cool down to room temperature, a mixture of $0.2 \mathrm{~mL}$ of $1 \%$ mannitol, $0.5 \mathrm{~mL}$ of $\mathrm{HNO}_{3}$ and $0.1 \mathrm{~mL} \mathrm{HF}$ was added to the boat for treating the sample residue. Then the mixture was made up to the required volume with Milli-Q ${ }^{\circledR}$ water for subse- quent analysis by ICP-OES. The detection limit of boron was $0.05 \mu \mathrm{g} / \mathrm{g}$ and the repeatability, expressed as the relative standard deviation (RSD), was about $4 \%$. The recoveries for the spike tests were obtained ranging from 98-102\%. A recently reported fusion method was adopted for validation of the developed method. The developed method was finally applied to the analysis of graphite powder samples for the determination of boron.

exported not be of nuclear grade under the Atomic Energy Act 1962. Therefore, a precise and accurate determination of boron in graphite requires a sensitive and reliable analytical method for its characterization as nuclear/non-nuclear grade.

It has been observed that boron is a difficult element to determine, especially when present at sub-ppm levels, and the major task is a sample preparation that prevents any loss of boron $(11,12)$. Due to this, the direct solid analysis-based techniques, such as laser ablation ICPMS, electrothermal (ETV)-ICP-MS, instrumental neutron activation analysis (INAA), wavelength dispersive X-ray fluorescence spectrometry (WDXRF), and total reflection $\mathrm{XRF}$, have been reported for the determination of trace impurities in graphite excluding boron $(1,2,13$ 16). Emission spectrographic-based methods have been developed for the determination of boron in graphite (17-19). Xin-Li et al. developed a slurry nebulization ICP-MS method for the direct determination of ultra-trace levels of boron in nuclear-grade graphite. However, this type of slurry preparation needs many parameters to be optimized and hence is not suitable for the analysis of samples on a routine basis (20).

For the analysis of chemically resistant materials such as graphite, extreme sample pre-treatments are required due to their complex and refractory nature (21-27). Microwave decomposition and fusion using $\mathrm{Na}_{2} \mathrm{CO}_{3} / \mathrm{NaHCO}_{3}$ or $\mathrm{Ba}(\mathrm{OH})_{2}$ are the two standard sample preparation methods used for the determi- 
nation of boron in refractory materials including graphite (28-31). However, due to the large quantities of flux employed in decomposing the sample, blanks are significantly increased, which limits its limits of detection (LODs). The resulting high salt content also poses problems, especially when the sample is to be introduced into ICP-based techniques, leading to non-spectroscopic interferences. More recently, Thangavel et al. (31) reported an alkali fusion method using $\mathrm{Na}_{2} \mathrm{CO}_{3}$ solution, followed by glycerol extraction, for the determination of boron in graphite powders with a detection limit of 0.09 $\mu \mathrm{g} \mathrm{g}^{-1}$. Although this method is suitable for boron determination in nuclear-grade graphite, a large number of steps and long sample preparation time ( $\sim 3 \mathrm{~h}$ per sample) limit its application for routine analysis. Thus, there is a great need for the development of simple and reliable sample preparation methods that can be used for routine analysis of graphite for boron.

In this study, a new sample preparation method based on oxidative pyrolysis (OP) has been developed for this purpose. In our previous investigations, the $\mathrm{OP}$ approach has been successfully utilized for the determination of mercury in organic-rich solid materials and for the multi-elemental analysis of boron carbide samples $(32,33)$.

We report here a simple and robust sample preparation method based on oxidative pyrolysis for decomposing the graphite matrix, followed by the determination of boron using ICP-OES. The total pyrolysis process was found to be very rapid when the typical temperature employed in a stream of oxygen was $\sim 400{ }^{\circ} \mathrm{C}$ and the matrix was completely removed without any loss of boron. To the best of our knowledge, this is the first study based on the utilization of the oxidative pyrolysis approach as a sample preparation methodology for the determination of boron in graphite samples.

\section{EXPERIMENTAL}

\section{Instrumentation}

The determination of boron, after decomposing the graphite matrix by the proposed oxidative pyrolysis approach, was carried out using an inductively coupled plasma optical emission spectrometer (ICP-OES) (Horiba Jobin Yvon JY-Ultima II, France), equipped with a cross-flow nebulizer and an HF-resistant cyclonic spray chamber. The instrumental operating conditions are listed in Table I. The sensitivity of the instrument was checked daily before analyzing the samples. The most sensitive spectral line of $249.773 \mathrm{~nm}$ was used for the determination of boron. The ICPOES instrument was chosen in the present work due to its high sensitivity and precision.

\section{Reagents and Standard Solutions}

Ultra-pure water with a specific resistance of $>18 \mathrm{M} \Omega-\mathrm{cm}$, generated using a Milli-Q ${ }^{\circledR}$ high purity water system (Millipore Corporation, Bedford, MA, USA), located in a class 100 area, was used for the preparation of all sample and standard solutions. Sub-boiled $\mathrm{HCl}$ and $\mathrm{HNO}_{3}$ were prepared in-house by sub-boiling distillation in quartz stills. GR grade HF (48\%, Merck, Mumbai, India) was used in treating the sample residue after the OP process. All reagents used in this work were of the highest available purity. Solutions of AR grade $\mathrm{Na}_{2} \mathrm{CO}_{3}$ and mannitol (Merck, India) were prepared by dissolving appropriate amounts in water. AR grade activated charcoal (SD FineChem Ltd., Mumbai, India) was used as the ignition aid for pyrolyzing the graphite samples. All containers were cleaned by soaking in a $20 \%$ nitric acid solution and then rinsed several times with ultrapure water before use. A boron standard stock solution (1000 $\mathrm{mg} \mathrm{L}^{-1}$ ) was obtained from Merck, Germany. The calibration solutions for boron were prepared just prior to analysis

TABLE I

Instrumental Operating conditions of the ULTIMA II ICP-OES

\begin{tabular}{|c|c|}
\hline Parameters & Specifications \\
\hline Generator & $40.68 \mathrm{MHz}$, solid-state, $1200 \mathrm{~W}$ power, water-cooled \\
\hline Torch & $\begin{array}{l}\text { Fully demountable, } 3.0 \mathrm{~mm} \text { i.d. injector, vertical, } \\
\text { radial view with total plasma view }\end{array}$ \\
\hline Optical System & $\begin{array}{l}\text { Czerny Turner Mounting, } 1 \mathrm{~m} \text { focal length, } \\
<5 \mathrm{pm} \text { for } 160-320 \mathrm{~nm} \text { and }<10 \mathrm{pm} \text { for } 320-800 \mathrm{~nm}\end{array}$ \\
\hline Detection & PMT detection with high dynamic detection system \\
\hline Gas Flows & $\begin{array}{l}\text { Plasma gas: } 12.5 \mathrm{~L} / \mathrm{min} \text {, } \\
\text { Auxiliary gas: } 0.8 \mathrm{~L} / \mathrm{min} \text {, } \\
\text { Sheath gas: } 0.3 \mathrm{~L} / \mathrm{min} \\
\text { Nebulizer gas flow: } 0.65 \mathrm{~L} / \mathrm{min}\end{array}$ \\
\hline Sample Introduction & $\begin{array}{l}\text { HF-resistant concentric nebulizer, } \\
\text { Cyclonic spray chamber, } \\
\text { Sample uptake rate }=1 \mathrm{~mL} / \mathrm{min}\end{array}$ \\
\hline Spectral Line for Boron & $249.773 \mathrm{~nm}$ \\
\hline
\end{tabular}


by sequential dilution of the stock standard with high purity water.

\section{Oxidative Pyrolysis Setup}

A schematic diagram of the oxidative pyrolysis setup is shown in Figure 1. The evolved oxygen passes through a trap containing mannitol and diluted nitric acid solution placed at the other end. A small tube protruded inside the pyrolysis chamber to insert a thermocouple for measuring the temperature. A sample boat made of quartz (40Lx25Wx4D mm) was used for holding the pellet. The main parts associated with this setup, namely flow meter and pyrolysis chamber and a mannitol trap, are linked with short segments of silicone tubing. All the graphite powder samples analyzed by the proposed approach were obtained from Analytical Chemistry Division of Bhabha Atomic Research Centre, Mumbai, India.

\section{General Procedure for Sample Preparation (pelletization and oxidative pyrolysis)}

Approximately $0.2 \mathrm{~g}$ of graphite sample was mixed with $\sim 0.15 \mathrm{~g}$ of carbon (in the form of activated charcoal) powder in a pre-cleaned and dry mortar after the addition of $0.25 \mathrm{~mL}$ of $20 \mathrm{mg} \mathrm{mL}^{-1} \mathrm{Na}_{2} \mathrm{CO}_{3}$ solution and $0.2 \mathrm{~mL}$ of $1 \%(\mathrm{w} / \mathrm{v})$ poly- vinyl alcohol (as binder). Then the sample mixture was thoroughly mixed to ensure complete coating of each graphite particle with $\mathrm{Na}_{2} \mathrm{CO}_{3}$. The sample mixture was dried under IR radiation until complete dryness and pressed into a $10-\mathrm{mm}$ diameter pellet using a hydraulic press (Aimil Ltd., Bangalore, India) at $75 \mathrm{~kg} \mathrm{~cm}^{-2}$ for $5 \mathrm{~min}$ utes. Blank pellets with only carbon powder were also prepared in the same way without the graphite material.

The sample pellet was placed on the boat and inserted into the pyrolysis chamber which was then closed as shown in Figure 1. Oxygen was fed into this system at a fixed flow rate of $\sim 300 \mathrm{~mL} \mathrm{~min}^{-1}$. The chamber was then heated using a Bunsen burner, placed under the sample boat, in the presence of the oxygen stream. After an initial heating from 1-2 minutes, the sample ignited with an intense and bright glow and the sample mixture was burnt completely within 5 minutes. The heating was stopped when the glow completely extinguished. After this pyrolysis step, the chamber was allowed to cool to room temperature and the boat was taken out. A mixture of $0.2 \mathrm{~mL}$ of $1 \%(\mathrm{w} / \mathrm{v})$ mannitol and $0.5 \mathrm{~mL}$ of concentrated $\mathrm{HNO}_{3}$ was added to the boat to treat the sam-

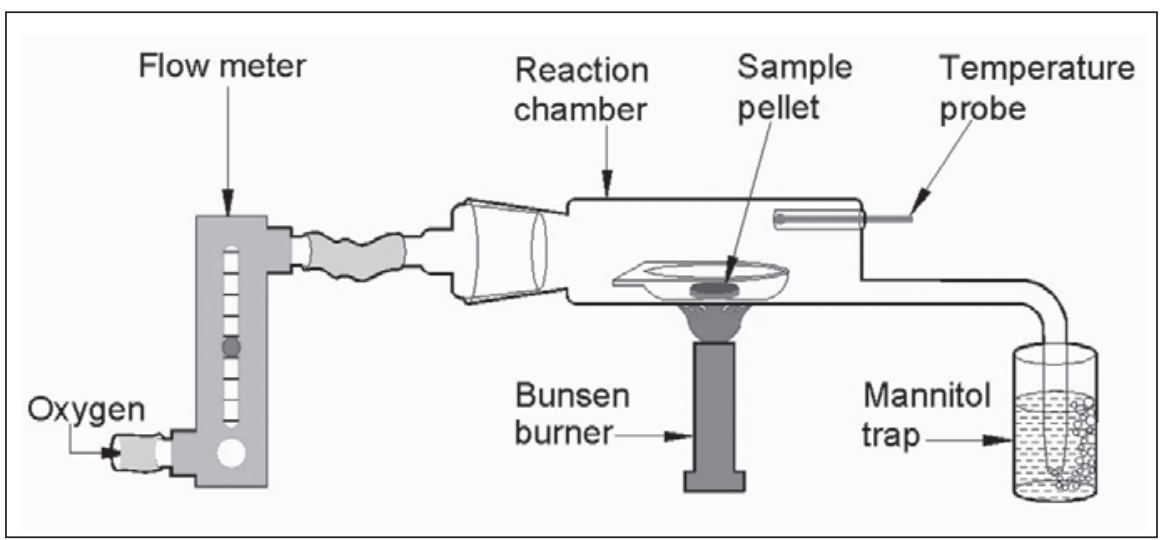

Fig. 1. Schematic diagram of the oxidative-pyrolysis setup for the determination of boron in graphite powders. ple residue, which was then transferred to a pre-cleaned screw-capped polypropylene tube. After adding $0.1 \mathrm{~mL}$ of $\mathrm{HF}$, the sample mixture was initially made up to $10 \mathrm{~mL}$ and further diluted appropriately with high purity water for subsequent analysis of boron by ICP-OES.

It is widely known that boron reacts with poly-hydroxyl compounds such as mannitol and forms complexes which suppress the volatilization of boron $(34,35)$. In the present study, a mixture of $10 \mathrm{~mL}$ of $0.02 \%(\mathrm{w} / \mathrm{v})$ mannitol and $2 \%$ (v/v) $\mathrm{HNO}_{3}$ was used as trapping solution for collection of the volatile species of boron, if any, during pyrolysis of the graphite sample. Process blank solutions were prepared in an identical way using a pellet made of only carbon powder. Analysis of the samples and blanks was carried out in triplicate. In the case of spiked experiments, the percentage recovery of boron after applying the proposed OP process was calculated as the ratio (\%) of the amount of boron obtained after the OP process and the amount of boron spiked.

In other cases, the percentage recovery $(\mathrm{R} \%)$ of boron after applying the proposed OP process was calculated using the following equation:

$$
\mathrm{R}(\%)=\frac{\text { Value by present method }}{\text { Value by fusion method }} \times 100
$$

Quantifications of the boron content in the graphite samples are based on a 5-point calibration graph obtained from the aqueous standards. A standard addition method was also applied in order to compensate for any possible matrix-related problems.

In order to determine the loss of boron, if any, during the OP process, a set of experiments was carried out by spiking known amounts of boron $(1-25 \mu \mathrm{g})$ into the high purity graphite powder 
(Alfa Aesar, 5N5 pure) before the pelletization step which was then subjected to the proposed OP method as described above. The resultant solutions, after suitable dilution, were analyzed by ICP-OES. Calibration plots were also obtained with the spiked samples and compared with those of pure aqueous boron standards.

\section{Sodium Carbonate Fusion Method for Validation}

For validation purposes, a recently reported sodium carbonate fusion method was adopted without any further modifications (31). Approximately $0.5 \mathrm{~g}$ of graphite powder and $2.5 \mathrm{~mL}$ of $10 \% \mathrm{Na}_{2} \mathrm{CO}_{3}$ were added to a nickel crucible. The sample powder and flux were stirred well to form a paste. Then the crucible was heated on an IR hot plate at $\sim 150{ }^{\circ} \mathrm{C}$ to complete dryness and then covered with a lid and heated in a muffle furnace at $\sim 900{ }^{\circ} \mathrm{C}$ for 1 hour. After allowing it to cool, $\sim 10 \mathrm{~mL}$ of water was added to the melt and heated over a hot plate at $\sim 150^{\circ} \mathrm{C}$ for complete dissolution of the fused contents. Then the sample solution was transferred to a high density polyethylene (HDPE) container and $1.5 \mathrm{~g}$ of glycerol was added, followed by heating on a water bath at $\sim 90{ }^{\circ} \mathrm{C}$ for about 30 minutes. After centrifugation, the clear supernatant solution was separated from the solid residue and made up to $10 \mathrm{~mL}$ using high purity water for subsequent analysis by ICP-OES. The process blank solutions were prepared under identical conditions but without the graphite sample. This process blank solution was also utilized for preparation of the standards for ICP-OES measurements to make the matrix-matched standards, thereby keeping the flux $\left(\mathrm{Na}_{2} \mathrm{CO}_{3}\right)$ concentration and the acidity in the standard solution used for calibration the same as that in the sample solution.

\section{RESULTS AND DISCUSSION}

Due to non-availability of a suitable reference material, a graphite powder, whose boron content was determined to be $\sim 46 \mu \mathrm{g} \mathrm{g}^{-1}$ of boron by the recently reported method (31), was used as the representative sample for optimizing various experimental parameters related to the OP process. All graphite samples used in this work were screened to obtain a particle size of $\leq 100 \mu \mathrm{m}$. The procedure for each run involved mixing appropriate amounts of carbon powder along with a solution of $\mathrm{Na}_{2} \mathrm{CO}_{3}$, pelletization and oxidative pyrolysis, followed by ICP-OES determination of boron. In all of the experiments, the efficiency of the proposed OP approach was established by calculating the percent recovery of boron.

\section{Development of Oxidative Pyrolysis Method - Preliminary Studies}

Initial attempts were made to pyrolyze the graphite powder sample ( $\sim 0.2 \mathrm{~g})$ singly with the setup shown in Figure 1. But the sample did not ignite even after heating it for more than 10 minutes. This could possibly be due to the high ignition temperature of graphite $\left(>800{ }^{\circ} \mathrm{C}\right)$. The maximum temperature that can be achieved with the existing system is about $600{ }^{\circ} \mathrm{C}$. Therefore, in order to generate a suitable temperature (i.e., $\sim 800{ }^{\circ} \mathrm{C}$ ) to ignite the graphite sample, it was blended with carbon powder whose ignition temperature is in the range of $350-400{ }^{\circ} \mathrm{C}$. Using this approach, the required temperature was achieved locally during the pyrolysis of carbon in the presence of an oxygen stream which was found to be sufficient for igniting the graphite powder. Even though mixing of the graphite and carbon improved the pyrolysis process to a great extent, a significant amount of un-burnt graphite (15-20\%) was still left in the boat at the end of the experiment, leading to incomplete recovery of boron (85-90\%). Complete burning of the graphite could not be achieved even after mixing higher quantities of carbon. This is possibly due to the rapid burning of carbon compared to graphite powder.

To overcome this problem, the graphite and carbon mixture was pressed into a pellet and the pyrolysis process carried out. Using this approach, the graphite-carbon mixture was completely ignited/burnt (>99\%, calculation based on the weight of the sample before and after treatment) and the resultant sample residue was treated with a mixture of $0.2 \mathrm{~mL}$ of $1 \%$ mannitol, $0.5 \mathrm{~mL} \mathrm{HNO}_{3}$, and $0.1 \mathrm{~mL} \mathrm{HF}$. After centrifugation, the supernatant was transferred to another pre-cleaned tube and diluted to the required volume (depending on the concentration of boron) for subsequent analysis by ICP-OES.

However, the recovery of boron was found to be only about $88 \%$. Among the different chemical forms of boron (e.g., boric acid, boron carbide, and metal boride), the major volatile species is boric acid with a boiling point of $\sim 300{ }^{\circ} \mathrm{C}$, therefore it may be lost during the pyrolysis process which occurs at a temperature of $\sim 400^{\circ} \mathrm{C}$. The low recovery of boron may be due to the loss of boron as volatile species (mainly in the form of boric acid) during the pyrolysis process. Hence, further studies were focused on controlling the loss of boron. It is well established that addition of an alkali such as $\mathrm{NaHCO}_{3}$ or $\mathrm{Na}_{2} \mathrm{CO}_{3}$ can prevent volatilization of boron during high temperature treatments (in this case the oxidative pyrolysis) due to the formation of non-volatile borax/sodium borates.

In the present study, $\mathrm{Na}_{2} \mathrm{CO}_{3}$ solution was added which has two advantages: (a) addition of $\mathrm{Na}_{2} \mathrm{CO}_{3}$ in the form of solution forms a homogeneous medium with the 
graphite and carbon mixture and (b) formation of $\mathrm{NaOH}$ occurs during the partial hydrolysis of $\mathrm{Na}_{2} \mathrm{CO}_{3}$ as shown in the following equation:

$$
\mathrm{Na}_{2} \mathrm{CO}_{3}+\mathrm{H}_{2} \mathrm{O} \rightarrow \mathrm{NaOH}+\mathrm{NaHCO}_{3}
$$

Since the melting point of $\mathrm{NaOH}$ is $318^{\circ} \mathrm{C}$, it reacts with boron during the oxidative pyrolysis process of graphite which occurs at $\sim 400{ }^{\circ} \mathrm{C}$ and forms non-volatile species of boron, resulting in quantitative recoveries.

Further experiments were therefore continued with the addition of a known amount of hydrolyzed $\mathrm{Na}_{2} \mathrm{CO}_{3}$ in the liquid phase to the mixture of graphite and carbon before pelletization in order to improve the recovery of boron. A significant increase in the recovery of boron (from $88 \%$ to $>98 \%$ ) was observed with the addition of $\mathrm{Na}_{2} \mathrm{CO}_{3}$. The concentration of $\mathrm{Na}_{2} \mathrm{CO}_{3}$ solution was also optimized in later optimization studies.

After these preliminary experiments, a systematic study was performed for the optimizing conditions related to pelletization (amount of carbon and concentration of alkali) and the oxidative pyrolysis (oxygen flow rate and sample mass) process for the quantitative recovery of boron. Among the acid mixtures tested for the treatment of the sample residue after the OP process, maximum recovery was obtained for boron with a mixture comprising $0.2 \mathrm{~mL}$ of $1 \%$ mannitol, $0.5 \mathrm{~mL}$ of $\mathrm{HNO}_{3}$, and $0.1 \mathrm{~mL} \mathrm{HF}$ which was used throughout the subsequent studies. The results of the analysis of the trapping solutions [mixture of $10 \mathrm{~mL}$ of $0.02 \%(\mathrm{w} / \mathrm{v})$ mannitol and $2 \%(\mathrm{v} / \mathrm{v}) \mathrm{HNO}_{3}$ ] by ICP-OES showed no significant traces of boron, indicating the absence of any volatile species during the $\mathrm{OP}$ process in the presence of $\mathrm{Na}_{2} \mathrm{CO}_{3}$.
Influence of Carbon Powder and Concentration of $\mathrm{Na}_{2} \mathrm{CO}_{3}$

The selection of carbon powder as igniter was due to its availability in pure form, low price, and minimal residue introduction to the final digests which limit interferences during the determination step. In order to achieve higher temperatures for complete pyrolysis of the graphite for quantitative recovery of boron, the amount of carbon powder was optimized in the range of $0.1-0.4 \mathrm{~g}$, keeping the weight of the representative graphite sample to $\sim 0.2 \mathrm{~g}$, the concentration of $\mathrm{Na}_{2} \mathrm{CO}_{3}$ solution $(0.25$ $\mathrm{mL}$ of $\left.20 \mathrm{mg} \mathrm{mL}^{-1}\right)$, and the oxygen flow rate $\left(\sim 300 \mathrm{~mL} \mathrm{~min}^{-1}\right)$ constant. The results clearly demonstrated that the recovery of boron significantly increased from $85 \%$ to $>98 \%$ when the weight of the carbon powder was varied from 0.1 to $0.4 \mathrm{~g}$ (sample to carbon ratio $1: 0.5$ to $1: 2$ ). As can be seen in Figure 2 , $0.15 \mathrm{~g}$ of carbon for processing $0.2 \mathrm{~g}$ of graphite sample (graphite to carbon powder ratio of $1: 0.75$ ) was found to be optimum for the quantitative recovery ( $>98 \%$ ) of boron. The low recoveries of boron with low amounts of carbon $(<0.15 \mathrm{~g}$ carbon for $0.2 \mathrm{~g}$ of

\section{Atomic}

graphite) may possibly be due to the incomplete oxidation of the graphite material.

The concentration of $\mathrm{Na}_{2} \mathrm{CO}_{3}$ is another important parameter as related to the recovery of boron and needs to be optimized in order to keep the minimum amount of flux in the final sample solution. The volume of $\mathrm{Na}_{2} \mathrm{CO}_{3}$ solution was optimized to $0.25 \mathrm{~mL}$ so that the sample mixture $(\sim 0.2 \mathrm{~g}$ of graphite sample and $\sim 0.15 \mathrm{~g}$ of carbon) gets properly wetted with the solution and forms a homogeneous paste to ensure complete coating of each graphite particle with $\mathrm{Na}_{2} \mathrm{CO}_{3}$. Based on the initial experiments, the concentration of $\mathrm{Na}_{2} \mathrm{CO}_{3}$ solution was varied from $5-40 \mathrm{mg} \mathrm{mL}^{-1}$ for a mixture of $0.2 \mathrm{~g}$ graphite and $0.15 \mathrm{~g}$ of carbon powder while keeping the volume of $\mathrm{Na}_{2} \mathrm{CO}_{3}$ solution constant at $0.25 \mathrm{~mL}$, and the general procedure was applied. After each OP run, the recovery of boron was calculated. From these experiments, it was found that an aliquot of $0.25 \mathrm{~mL}$ of $20 \mathrm{mg} \mathrm{mL}^{-1}$ $\mathrm{Na}_{2} \mathrm{CO}_{3}$ solution (i.e., $5 \mathrm{mg}$ absolute or $2.5 \%$ for processing of $0.2 \mathrm{~g}$ graphite sample) yielded a quantitative recovery of boron. For processing of a higher amount of

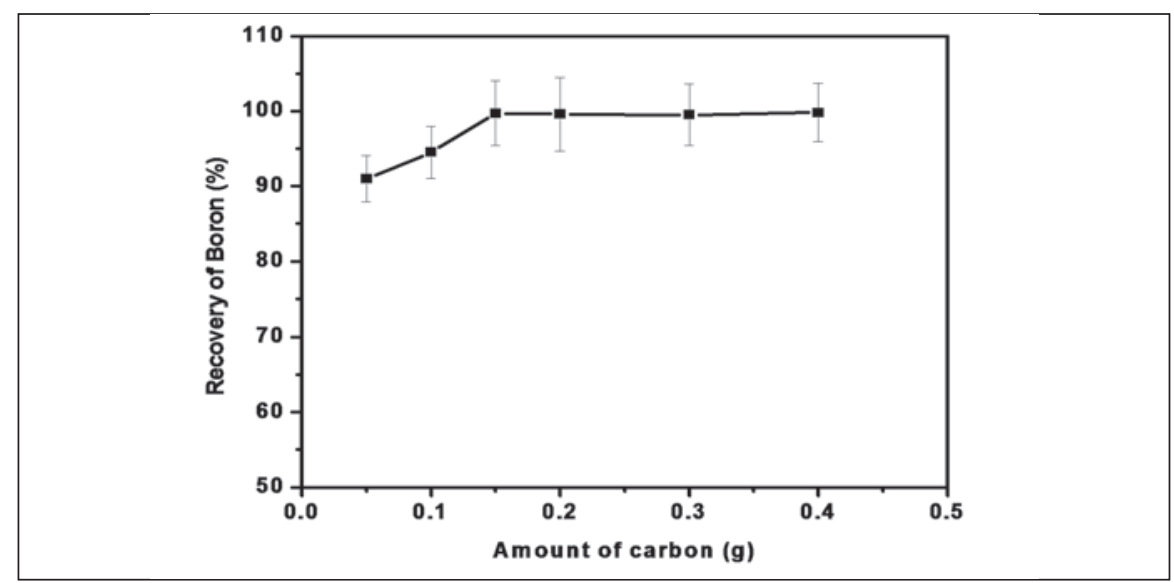

Fig. 2. Effect of amount of carbon powder on the recovery of boron from the representative graphite sample.

Weight of representative graphite sample $=0.2 \mathrm{~g}$; amount of $\mathrm{Na}_{2} \mathrm{CO}_{3}$ added $=250 \mu \mathrm{L}$ of $20 \mathrm{mg} \mathrm{mL}^{-1}$ solution; size of the pellet $=10 \mathrm{~mm}$; oxygen gas flow rate $=300 \mathrm{~mL} \mathrm{~min}{ }^{-1}$. 
graphite sample, a corresponding concentration of $\mathrm{Na}_{2} \mathrm{CO}_{3}$ was maintained.

\section{Optimization of Oxygen Flow Rate and Sample Mass for the Oxidative Pyrolysis Process}

The ignition temperature of carbon varies between $350-500{ }^{\circ} \mathrm{C}$ depending on the experimental conditions. In gaseous products, such as $\mathrm{CO}_{2}, \mathrm{CO}$, and water vapor, carbon is released when it reacts with oxygen at these temperatures. It has been observed that pyrolysis under high concentration of oxygen could greatly improve the pyrolysis process characteristics such as high reaction temperatures and reaction rates which contribute to more complete destruction and conversion of the substance. Hence, oxygen-enhanced pyrolysis has been used in the present method for the decomposition of the graphite material, followed by the quantitative determination of boron by ICP-OES.

The presence of oxygen is therefore essential for the complete ignition of the graphite powder sample. During ignition, graphite gets oxidized to $\mathrm{CO}_{2}$ and escapes to the atmosphere, thereby eliminating the graphite matrix significantly and leaving behind the analyte of interest (boron in this case). However, at high flow rates of oxygen, there is every possibility of carrying away the sample ashes (generated during the OP process) which may affect the recovery of boron. Similarly, the OP process may take longer when a low flow rate of oxygen is maintained which limits the sample throughput. Therefore, the influence of the oxygen flow rate on the quantitative recovery of boron was investigated with the representative graphite sample using the general procedure by keeping other variables constant. In all of the cases, heating was stopped when the glow (generated during the OP process) was com- pletely extinguished. The results obtained when the oxygen flow rate was varied from 100 to $600 \mathrm{~mL} \mathrm{~min}^{-1}$ (controlled by a rotameter) are presented in Figure 3 . As can be seen, the recovery of boron was quantitative ( $>98 \%$ ) when the oxygen flow rate was $300 \mathrm{~mL} \mathrm{~min}^{-1}$, which was used throughout thse studies.

Due to the complex nature and the high ignition temperature of the graphite sample, it is possible that the amount of sample mass may influence the quantitative recovery of boron. Hence, the effect of the mass of the sample taken for the OP process with the existing setup (as shown in Figure 1) upon the recovery of boron was investigated. To study this effect, the proposed pyrolysis method was carried out with a different sample mass ranging from 0.2 to $1.0 \mathrm{~g}$ using the optimized values of other parameters, such as the sample to carbon ratio ( $1: 0.75)$, appropriate volume of $20 \mathrm{mg} \mathrm{mL}^{-1} \mathrm{Na}_{2} \mathrm{CO}_{3}$ solution and oxygen flow-rate $\left(\sim 300 \mathrm{~mL} \mathrm{~min}^{-1}\right)$. A pellet of $10 \mathrm{~mm}$ in diameter was made up using up to $0.4 \mathrm{~g}$ of graphite powder, while 20-mm diameter-sized pellets were made of $>0.5 \mathrm{~g}$ of sample for carry- ing out the OP process. From these studies, it was clearly evident that for the studied range of sample mass, oxidation of the graphite powder proceeds in a similar fashion with a quantitative recovery of boron (>98\%). It was also observed that a sample mass of up to $1 \mathrm{~g}$ was suitable for the quantitative determination of boron by the present arrangement. All variables studied relating to the proposed oxidative pyrolysis method and the optimum values obtained are listed in Table II.

\section{Analytical Figures of Merit}

Following the optimization of the experimental conditions related to the oxidative pyrolysis approach, the analytical characteristics were obtained for boron. A calibration plot was generated in the concentration range of 0 (i.e., analytical blank) to $100 \mathrm{ng} \mathrm{mL}^{-1}(10,25,50$, $75,100 \mathrm{ng} \mathrm{mL}^{-1}$ ) for quantification of boron. The response function $(y=1755 x-148.8)$ shows good linearity with a satisfactory correlation coefficient $\left(R^{2}=>0.9995\right)$. The concentration of boron in the final process blank solutions (after processing of $0.2 \mathrm{~g}$ carbon powder using the general procedure) was found to be significantly low $(n=3)$.

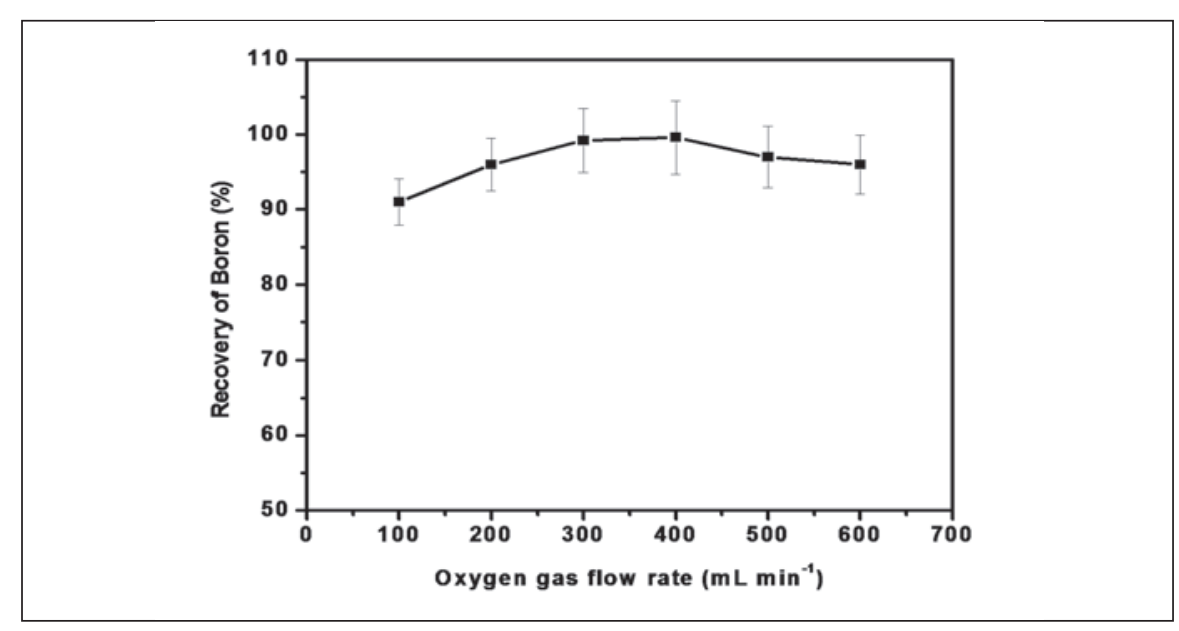

Fig. 3. Influence of oxygen gas flow rate on the recovery of boron from the representative graphite sample.

Weight of representative graphite sample $=0.2 \mathrm{~g}$, weight of carbon $=0.15 \mathrm{~g}$;

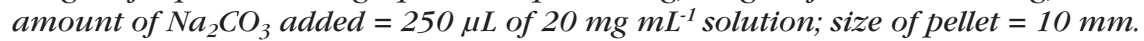


Spiked recovery studies were carried out with the addition of $1,5,10$, and $20 \mu \mathrm{g}$ of boron $(0.02$, $0.1,0.2$, and $0.4 \mathrm{~mL}$ of a $50 \mu \mathrm{g} \mathrm{mL}^{-1}$ boron standard solution) to the $\sim 0.2 \mathrm{~g}$ of high purity graphite powder (Alfa Aesar, 99.9995\% purity) containing $0.1 \mu \mathrm{g} \mathrm{g}^{-1}$ of boron. The spiked graphite powder samples were taken through the complete sample preparation (pelletization, followed by the oxidative pyrolysis) and ICP-OES analysis. As seen in Table III, recoveries of $98 \%$ and better were obtained for boron, demonstrating that there was no significant loss during the sample preparation procedure. The slopes of the calibration plots for boron obtained with the standards prepared in Milli-Q water, process blank solution, and standards prepared from spiked experiments, showed that they were not significantly different, thus facilitating the use of aqueous standards for the quantification of boron. These studies clearly indicated (a) no significant losses of boron and (b) the absence of matrix interference due to the complete oxidation of the graphite during the pyrolysis process.

According to the IUPAC definition, the limits of detection (LODs) were calculated as the concentration of the analyte yielding a signal equivalent to three times the standard deviation of the blank value

TABLE III

Recovery of Boron From Spiked Graphite Samples After Passing Through Oxidative Pyrolysis Process and ICP-OES Determination

\begin{tabular}{ccc}
\hline $\begin{array}{c}\text { Added } \\
(\mu \mathrm{g})\end{array}$ & $\begin{array}{c}\text { Found } \\
(\mu \mathrm{g})\end{array}$ & $\begin{array}{c}\text { Recovery } \\
(\%)\end{array}$ \\
\hline 1 & $1.1 \pm 0.1$ & 101 \\
5 & $4.9 \pm 0.3$ & 98 \\
10 & $10.2 \pm 0.5$ & 102 \\
20 & $19.8 \pm 0.8$ & 99 \\
\hline
\end{tabular}

$(3 \sigma)$. The LOD of the present OP method in conjunction with ICPOES was $0.05 \mu \mathrm{g} \mathrm{g}^{-1}$. The repeatability expressed as the relative standard deviation ( $R S D, n=6$ ) was $<5 \%$ for boron at the concentration levels of $10 \mathrm{ng} \mathrm{mL}^{-1}$.

The analysis results of the graphite powders containing varied concentrations of boron (3-70 $\mu \mathrm{g} \mathrm{g}^{-1}$ ) using reported and developed methods are listed in Table IV. As can be seen, no statistical difference at the $95 \%$ confidence level was observed between the results obtained with the proposed and the reported fusion methods.

\section{Atomic Apectroscopy \\ 1 Vol. 35(3), May/June 2014}

\section{Comparison of Proposed OP Method With Reported Fusion Methods}

A comparison between the proposed method and various reported fusion methods is shown in Table $\mathrm{V}$. As can be seen, a reagent mixture of $0.5 \mathrm{~mL}$ of $\mathrm{HNO}_{3}, 0.1 \mathrm{~mL}$ of $\mathrm{HF}$, and $0.2 \mathrm{~mL}$ of $1 \%$ mannitol was found to be sufficient to recover $>98 \%$ of boron from the ignited graphite sample residue. Hence, high amounts of concentrated acids are not required in the present approach and resulted in lower blank values which are important in order to achieve low detection limits. However, the methods reported by different authors $(3,29,31)$ require very high amounts of salts (up to 1:16 sample to flux ratio)

TABLE II

Optimization of Variables for the Oxidative Pyrolysis Process, Range Studied and Optimum Values Obtained

\begin{tabular}{lcc}
\hline Parameter & Range Studied & Optimum Value \\
\hline $\begin{array}{l}\text { Graphite: Carbon } \\
\text { powder ratio }\end{array}$ & $1: 0.5,1: 0.75$, & $1: 0.75$ \\
$\begin{array}{l}\text { Concentration of } \mathrm{Na}_{2} \mathrm{CO}_{3} \\
\text { solution (mg per g of sample) }\end{array}$ & $5-40$ & 25 \\
Oxygen flow rate $\left(\mathrm{mL} \mathrm{min}{ }^{-1}\right)$ & $100-600$ & 300 \\
Sample weight $(\mathrm{g})$ & $0.1-1.0$ & $<1$ \\
\hline
\end{tabular}

TABLE IV

Comparison of Boron Values Obtained

by Developed Oxidative Pyrolysis and Fusion Methods $(n=3)$

\begin{tabular}{lccc}
\hline Graphite Sample No. & $\begin{array}{l}\text { Present } \\
\text { Method }\end{array}$ & $\begin{array}{l}\text { Fusion } \\
\text { Method } \\
(\text { Ref. 31) } \\
\left(\mu \mathrm{g} \mathrm{g}^{-1}\right)\end{array}$ & Recovery \\
& $\left(\mu \mathrm{g} \mathrm{g}^{-1}\right)$ & $71.3 \pm 3.4$ & 101.1 \\
\hline 1. & $72.1 \pm 2.7$ & $60.7 \pm 3.1$ & 99.5 \\
2. & $60.4 \pm 1.8$ & $50.5 \pm 2.8$ & 101.4 \\
3. & $51.2 \pm 2.1$ & $45.7 \pm 2.9$ & 99.3 \\
4. (Representative sample) & $45.4 \pm 2.2$ & $8.7 \pm 0.6$ & 98.8 \\
5. & $8.6 \pm 0.4$ & $3.8 \pm 0.4$ & 102.6 \\
6. & $3.9 \pm 0.3$ & & \\
\hline
\end{tabular}

Graphite sample: carbon weight ratio $=200: 150 \mathrm{mg}$.

Amount of $\mathrm{Na}_{2} \mathrm{CO}_{3}$ added $=0.25 \mathrm{~mL}$ of $20 \mathrm{mg} \mathrm{mL}^{-1}$ solution.

Size of pellet $=10 \mathrm{~mm}$. 
such as $\mathrm{Na}_{2} \mathrm{CO}_{3}$ and $\mathrm{Ba}(\mathrm{OH})_{2}$ for the complete processing of the same amount of sample thereby resulting in high concentrations of dissolved solids in the final digests which is detrimental to the trace level determination of boron. The poor precision in these reported methods could be due to the use of large amounts of flux for fusing the samples and the high dilution factors used. The LOD obtained for boron using the developed method was lower than those reported in the literature, demonstrating the capability of the proposed OP method.

Sample preparation time is an important consideration for routine analysis. In this sense, the fusionbased sample decomposition methods require about 3-6 hours of heating for processing the samples for analysis which restricts the sample throughput. However, the proposed method has a rapid turnaround time of about 20 minutes for sample preparation (pelletization and oxidative pyrolysis, followed by ICP-OES analysis) and hence is suitable for the analysis of graphite for boron on a routine basis.

\section{CONCLUSION}

A simple and efficient oxidative pyrolysis (OP) method for the determination of boron in graphite powders by ICP-OES has been demonstrated. The analytical response function for boron illustrates good linearity with satisfactory correlation coefficients and LODs at the nanogram level $\left(0.05 \mu \mathrm{g} \mathrm{g}^{-1}\right)$. The minimum reagent consumption $\left(0.5 \mathrm{~mL} \mathrm{HNO}_{3}, 0.1 \mathrm{~mL}\right.$ $\mathrm{HF}$, and $0.2 \mathrm{~mL}$ of $1 \%$ mannitol) and reduced use of time ( 20 minutes including the pelletization and pyrolysis process) make this procedure promising for obtaining high quality results with a high sample throughput. To the best knowledge of the authors, no other digestion procedure for graphite results in
TABLE V

Comparison Between Reported and Proposed Oxidative Pyrolysis Methods for the Determination of Boron in Graphite Powders

\begin{tabular}{|c|c|c|c|c|}
\hline Parameter & $\begin{array}{l}\text { Method } 1 \\
\text { (Ref. 3) }\end{array}$ & $\begin{array}{l}\text { Method } 2 \\
\text { (Ref. 29) }\end{array}$ & $\begin{array}{l}\text { Method } 3 \\
\text { (Ref. 31) }\end{array}$ & $\begin{array}{l}\text { Present } \\
\text { Method }\end{array}$ \\
\hline $\begin{array}{l}\text { Weight of } \\
\text { Sample (g) }\end{array}$ & 0.25 & 0.2 & 2 & 0.2 \\
\hline Reagents & $\begin{array}{l}\mathrm{Na}_{2} \mathrm{CO}_{3}+ \\
\mathrm{Na}_{2} \mathrm{O}_{2} \text { (flux) } \\
\text { Sample to } \\
\text { flux ratio } \\
1: 16\end{array}$ & $\begin{array}{l}5.6 \mathrm{~mL} \text { of } \\
\text { saturated } \\
\mathrm{Ba}(\mathrm{OH})_{2} \\
\text { solution }\end{array}$ & $\begin{array}{l}\mathrm{Na}_{2} \mathrm{CO}_{3} \\
\text { Sample to } \\
\text { flux ratio } \\
1: 0.5 \\
\text { Amount of } \\
\text { glycerol } 1.5 \mathrm{~g}\end{array}$ & $\begin{array}{l}\text { Sample to } \\
\text { carbon ratio } \\
1: 0.75, \\
5 \mathrm{mg} \text { of } \\
\mathrm{Na}_{2} \mathrm{CO}_{3}\end{array}$ \\
\hline $\begin{array}{l}\text { Sample Pre- } \\
\text { paration time (h) }\end{array}$ & $5-6$ & 3 & $3-4$ & $20 \min ^{\mathrm{a}}$ \\
\hline $\begin{array}{l}\text { Detection } \\
\text { Technique }\end{array}$ & $\begin{array}{l}\text { Potentiom- } \\
\text { etry }\end{array}$ & ICP-OES & ICP-OES & ICP-OES \\
\hline $\operatorname{LOD}\left(\mu \mathrm{g} \mathrm{g}^{-1}\right)$ & - & 1 & 0.09 & 0.05 \\
\hline
\end{tabular}

${ }^{\text {a }}$ IR lamp dyring time of about 5 minutes is included.

this type of performance with minimal generation of acid residues; thus is also in accordance with "green chemistry" recommendations. In view of its rapidity, lowered blank values, and absence of matrix-related interferences, the developed procedure can be a superior alternative to the time-consuming fusion methods and is highly suitable for routine analysis of boron in graphite samples.

\section{ACKNOWLEDGMENT}

The authors are thankful to Dr. Sunil Jai Kumar, Head, NCCCM, for his constant support and encouragement. We would like to thank colleagues from the Analytical Chemistry Division, BARC, for providing the graphite samples used in this work. 
Received February 25, 2014

\section{REFERENCES}

1. U. Schaffer and V. Krivan, Fresenius J. Anal. Chem. 371, 859 (2001).

2. C. Pickhardt, J. S. Becker, Fresenius J. Anal. Chem. 370, 534 (2001).

3. P. L. Buldini and D. Ferri, Microchem. J. 25, 143 (1980).

4. M. Watanabe and A. Narukawa, Analyst 125, 1189 (2000).

5. K. Watanabe and J. Inagawa, Analyst 121, 623 (1996).

6. A. Bolewski Jr., M. Ciechanowski, A. Dydejczyk, A. Kreft, Nucl. Instr. and Meth. in Phys. Res. B, 237, 602 (2005).

7. B. T. Kelly, Carbon 20, 3 (1982).

8. D. D. Dijulio and A. Hawari, J. Nucl. Mater. 392, 225 (2009).

9. C. Goodwin, A. Barkatt and M. Al-Sheikhly, Rad. Phy. Chem. 90, 38 (2014).

10. Model protocol additional to the agreement(s) between state(s) and the International Atomic Energy Agency for the application of safe guards, INFCIRC/540, IAEA, Vienna, September 1997.

11. D. Darbouret and I. Kano, J. Anal. At. Spectrom. 15, 1395 (2000).

12. R. M. Rao, S. K. Aggarwal, Talanta 75, 585 (2008).

13. W. Bogershausen, R. Cicciarelli, B. Gercken, E. Konig, V. Krivan, R. Muller-Kafer, J. Pavel, H. Seltner and J. Schelcher, Fresenius J. Anal. Chem. 357, 266 (1997).

14. A. D. Shinde, R. Acharya, R. Verma and A. V. R. Reddy, J. Radioanal. Nucl. Chem. 294, 409 (2012).
15. V. Natarajan, K. Porval, Y. babu, B. Rajeswari, B. A. Bhavale, M. Kumar, S. V. Godbole and V. K. Manchanda, Appl. Radiat. Isot. 68, 1128 (2010).

16. B. J. Lewis, J. R. Mciver and L. A. Joo, Carbon 20, 151 (1982).

17. C. Feldman and J. Y. Ellenburg, Anal. Chem. 27/11, 1714 (1955).

18. G. Rossi and G. Soldani, Analyst (London) 97, 124 (1972).

19. F. Gianni and F. Potenza, Anal. Chim. Acta 25, 90 (1961).

20. L. Xin-Li, D. Tai-Cheng, H. Yi, J. Xio-Yu, Z. Wei-Na and C. HangTing, Chin J. Anal. Chem. 38/5, 693 (2010).

21. E. S. Gladney, E. T. Jurney and D. B. Curtis, Anal. Chem. 48 (1976) 2139

22. J. C. Mills, Anal. Chim. Acta 183, 231 (1986).

23. B. Zarcinas and B. Cartwright, Analyst 112, 1107 (1987).

24. J. N. Walsh, Analyst 110, 959 (1995).

25. A. Domenech-Carbo, S. Sanchez-Ramos, D. J. YusaMarco, M. Moya-Moreno, J. V. Gimeno-Adelantado and F. Bosch-Reig, Anal. Chim. Acta 501, 103 (2004).

26. ASTM C1233-09, 2011, Standard practice for determining equivalent boron contents of nuclear materials, Annual Book of ASTM standards, Vol. 12-01.

27. Z. Hladky and M. Fisera, J. Anal. At. Spectrom. 118, 827 (1994).

28. G. A. Tambe, K. Venkatesh and P. Ravindran, Exploration and Research for Atomic Minerals 19, 191 (2009).

29. K. Venkatesh, S. A. Kumar, S. D. Kumar, R. Kameswaran, A. V. R. Reddy, Sanjiv Kumar, R. Babu and V. Nataraju, Exter- nal Report (BARC/2013/E/004) published by Bhabha Atomic Research Centre (BARC), Mumbai, India.

30. G. S. Kamble, S. P. Pandey, N. Thakur, S. A. Kumar, K. Venkatesh, S. D. Kumar, R. Kameswaran and A. V. R. Reddy, AIP Conf. Proc. 1538, 30 (2013).

31. S. Thangavel, K. dash, S. M. Dhavile and A. C. Sahayam, Anal. Methods, 5, 5799 (2013).

32. M. V. Balarama Krishna,

K. Chandrasekaran,

G. Venkateswarlu and D. Karunasagar, Anal. Methods 4, 3290 (2012).

33. M. V. Balarama Krishna, G. Venkateswarlu, S. Thangavel and D. Karunasagar, Anal. Methods 5, 1515 (2013).

34. T. Ishikawa and E. Nakamura, Anal. Chem. 62, 2612 (1990).

35. W-C. Wei, C-J. Chen and M-H. Yang, J. Anal. At. Spectrom. 10, 955 (1995). 